\title{
Is hermeneutiek nog ergens goed voor?
}

\author{
E. Talstra
}

\begin{abstract}
Is Biblical Hermeneutics still a meaningful discipline? Modern studies in hermeneutics either try to teach us how we can still speak about God in modern society, or that we should accept our limited abilities to speak about God at all. This article claims that these options separate God from the long history of biblical texts and contexts where $\mathrm{He}$, as 'I,' addresses Israel as 'you'. In his recent book on reading the Bible, Arnold Huijgen concentrates on the soul rather than on the ratio as an instrument for reading the Bible. Though agreeing with Huijgen's criticism of modern rationalistic hermeneutics, this article does not see why the soul should take over the role of biblical scholarship when reading the Bible.
\end{abstract}

\section{Bijbellezen - afstand en ontmoeting}

Hoe beginnen we met het lezen van de Bijbel? Op zoek naar argumenten, wanneer de kerk een reactie moet geven op maatschappelijke of morele uitdagingen van onze eigen tijd? In de verwachting dat ik geraakt word en er nu nieuw licht op mijn bestaan gaat schijnen? Of, wat minder individueel, in de verwachting dat ik iets ga zien van het grotere verhaal van Gods omgang met de mensen en de wereld?

Het recente werk van Arnold Huijgen ${ }^{1}$ over gelovige omgang met de Bijbel, maakt zulke vragen weer acuut. Gaat het in ons bijbellezen om redeneringen, theologische antwoorden of religieuze bevestiging? Huijgen bepleit dat het lezen van de Bijbel in de eerste plaats een activiteit op zichzelf is, een vorm van vertrouwelijke omgang. Daarmee raakt hij aan het werk van exegeten. Dat wil zeggen: het belang van open en aandachtig lezen gaat aan alle andere theologische belangen vooraf, dat zal iedere bijbelwetenschapper beamen. Maar is aandachtig lezen vervolgens ook gelovig omgaan met de

1 Arnold Huijgen, Lezen en laten lezen. Gelovig omgaan met de Bijbel, Utrecht, 2019. Zie de inleiding over zijn thema, 'concern' (16); de tegenstelling ratio en geloof, 17-18; de stelling over 'ontvankelijkheid', 19. 
Bijbel? Huijgen heeft de indruk dat door de behoefte aan antwoorden op actuele vragen, het vak hermeneutiek, de theorie van de uitleg van de Bijbel, in kerk en theologie soms zo rationalistisch wordt, dat het geloof daarin geen ruimte meer krijgt. Bij 'hermeneutiek' heb ik dezelfde aarzelingen als Arnold Huijgen. Helpt een analytische techniek, een leesmethode ons werkelijk aan een beter verstaan van de Bijbel? Of is het vooral een inhoudelijk filter ter wille van de actualiteit?

Huijgen poneert daartegenover de 'stelling' dat het lezen van de Schrift geen kwestie is van techniek of methode, maar een zaak van ontvankelijkheid, de bereidheid om jezelf 'te laten lezen' door de Bijbel. Het pleidooi voor gelovige ontvankelijkheid ondersteun ik, maar hier begint het contact met het werk van exegeten toch ook te schuren. Je kunt, behalve met rationalistisch opererende hermeneuten, ook een theologisch probleem hebben met die bijbelwetenschappers die zich liever niet over geloof uitlaten, dat besef ik. Maar hoe dan verder? Het blijft immers de vraag of gelovig bijbellezen zonder kennis en methode ergens toe leidt. Ook met een houding van ontvankelijkheid kan ik niet eenvoudig over de lange geschiedenis van de teksten en hun gelovige schrijvers en lezers heen springen. Die geschiedenis is een niet weg te denken onderdeel van de teksten en van de exegese. En, of we dat nu leuk vinden of niet, het historisch-kritisch bijbelonderzoek en de vele nieuwe tekstgegevens die we sinds de negentiende eeuw hebben leren kennen, betekenen voor ons nu nieuw en serieus theologisch huiswerk dat Luther of Calvijn nog niet hoefden te maken. Daarom formuleer ik een andere stelling: bijbelonderzoek doen we niet uit rationalistische eigenwijsheid, maar vanwege de vele tekstgegevens die er liggen en door hun verscheidenheid vragen oproepen. Dat leidt tot nieuwsgierigheid naar het ontstaansproces van de Bijbel zelf, tot meer inzicht in de complexe Bijbel zoals die er nu ligt en daarmee ook tot eerbied voor deze gegeven Bijbel als Woord van God.

Met de laatste zin zal niet iedere bijbelonderzoeker het eens zijn, maar voor een theoloog hoort die er wel bij. De ontstaansgeschiedenis van de Bijbel is het vertrekpunt van de theologie en niet een te negeren puzzel vooraf. Want ook als we met Huijgen het aandachtig bijbellezen zonder een direct hermeneutisch belang als uitgangspunt hebben, dan blijft toch de eerste ervaring met bijbelteksten de ervaring van afstand. Theologisch is dat een nuttige ervaring die je, vanwege de vragen die zij oproept, niet kunt overslaan. Ben ik als bijbellezer niet bezig met gesprekken van heel vroeger, tussen anderen? Ben ik wel in beeld als adres? Als God 'ik' zegt en een 'jij' aanspreekt, waar sta ik dan als lezer? Een voorbeeld is de manier waarop God de tekst van de 'Tien Woorden' begint in Exodus 20:2. 
'Ik ben Jнwн jouw God, ik, die jou heb bevrijd uit Egypte, uit het slavenbestaan. Jij mag er in mijn aanwezigheid geen vreemde godheid op na houden.'

Ik lees nu wel deze tekst, maar ikzelf ben toch niet uit Egypte bevrijd? Word ik dan hier met die geboden wel aangesproken als 'jij'?

Hermeneutiek problematiseert vooral het 'ik' van de lezer van de tekst: wordt die wel aangesproken? En hoe dan? Mijn voorstel is om eerst de dialoog in de tekst serieus te nemen, om zo ook onze ervaring van afstand tot de tekst serieus te nemen en niet meteen zelf een dialoog met de tekst te beginnen. Want dan staat de 'ik' in de tekst meteen buitenspel. Vaak wordt in kerk en liturgie en ook in publieke discussies over 'de geboden' de historische afstand tussen tekst en lezer eenvoudig genegeerd. De eerste zin met het 'ik' van JHwH over de uittocht, wordt weggelaten. Het effect is dat de geboden anders worden: contextvrije opdrachten, die hun gezag aan kerk of traditie ontlenen en niet aan JHwH die zichzelf hier introduceerde als bevrijder en 'ik' zei. Dat misverstand is te zien in de Trouw-interviews door Arjan Visser. ${ }^{2}$ Consequent is in alle interviews het begin van de tekst: 'Toen sprak God ... 'Ik ben JHwH jouw God,...' weggelaten. Elk interview valt zo meteen met de deur in huis bij de geboden in de protestantse of rooms-katholieke ordening. ${ }^{3}$ Op die manier ontstaat een tekst met een algemene morele, religieuze pretentie en zo krijgen we vervolgens alleen de reacties van de geïnterviewde te lezen over wat kerk en opvoeding allemaal ooit verlangden. Vaak heel boeiend, soms grof, maar de vraag blijft: heeft iemand Exodus 20 weleens compleet gelezen, met inleiding en context? Een fundamenteel stuk biografie van God met Israël wordt zo vervangen door de persoonlijke biografie van de geïnterviewde met bepaalde herinneringen aan de kerk. Dat is te haastig. Die persoonlijke verhalen zijn voer voor hermeneuten: 'Wat betekent voor jou ...?'4 Maar ze genereren een negatief soort bijbellezing, juist omdat de kerkelijke, liturgische pretentie van een tijdloze en voor iedereen direct geldige Bijbel de huidige lezer op het verkeerde been zet: 'Ik hoor mij

2 Arjan Visser, De Tien Geboden. Gesprekken met schrijvers, Amsterdam 2011.

3 In de catechismus van de RK Kerk worden de geboden tijdloos en contextloos samengevat. Dat is de versie die Arjan Visser gebruikt voor geïnterviewden van RK huize. Vgl. Catechismus van de Katholieke Kerk, Nederlandse uitgave, Kampen 2008. 'Ik ben de Heer uw God. Gij zult geen afgoden vereren, maar Mij alleen aanbidden en boven alles beminnen.' Al staat er dan nog wel “ik”, er is geen spoor van Exodus of geschiedenis meer te ontdekken.

4 Sake Stoppels, e.a. (red.), De Bijbel in Nederland. Reflecties over het gebruik van de Bijbel in kerk en cultuur, Haarlem 2018. 
door zulke teksten aangesproken te voelen, maar ik kan er niet zoveel mee.'

Daarom is die eerste ervaring van een lezer, dat er afstand is tussen ons en de oorspronkelijke adresseringen van de bijbeltekst, niet onhandig, niet ongelovig, maar realistisch en nuttig. Zij zou ons nieuwsgierig moeten maken en ons helpen om niet direct het eigen 'ik' tot belanghebbende lezer te verklaren. We lezen in Exodus 20 immers in de biografie van God en Israël. En het is een gewone opdracht voor elke lezer van welk boek dan ook, om eerst de spelers in de tekst aandachtig te volgen om te zien wat er tussen hen op het spel staat. Beginnen bij het begin: de 'ik' die de tekst opent. 'Ik' als lezer, kom nog wel aan de beurt.

De vele teksten waarin God zichzelf introduceert met 'ik', horen bij heel verschillende bladzijden uit de biografie die Bijbel heet. Bladzijden over bevrijding en leefregels, over teleurstellingen en nieuw begin, over dood en leven. In de theologie zijn zulke bladzijden te vaak een aanleiding om alleen conclusies te trekken over de status van die ene speler, Israël, uitgelegd als 'de mens' in het algemeen, die al of niet deugt. Maar we doen de Bijbel meer recht door eerst de hoofdrolspeler, JHWH, proberen te volgen en misschien verwondering te ontwikkelen.

In het boek Hosea (11) vertelt God over Israël en over zichzelf, door zijn teleurstelling te uiten en vragen te stellen bij hun gemeenschappelijke geschiedenis. Hij doet dat ook hier door nadrukkelijk 'ik' te zeggen. Soms alleen grammaticaal via een werkwoord, maar twee keer (vers 3 en 9) komt de 'ik' heel expliciet voor: 'ānoki, net als in Exodus 20.

1. Toen Israël kind was hield ik van hem. En uit Egypte heb ik mijn zoon geroepen.

2. Riep men hen, net zo hard gingen ze hun eigen weg: offeren aan de Baäls, reukoffers brengen voor de godenbeelden. (vers 2 is een vertaalpuzzel)

3. Terwijl ikzelf Efraïm heb leren lopen en hen in de armen heb genomen. $[\ldots]$

9. Ik ga mijn laaiende woede niet uitvoeren; ik zal Efraïm niet opnieuw vernietigen. $I k$ ben immers God en niet een mens.

Zo krijg je als lezer steeds iets van God te zien. God is in dispuut, met zijn volk, maar ook met zichzelf. Laaiend over ontrouw, maar, gaat mijn volk dat overleven? Gods woorden klinken in context, in de concrete gang van de biografie met zijn volk. 'Ik zal Efraïm in leven houden, ik ben immers God.' De prachtige theologische inleiding op het boek Deuteronomium (4) laat iets dergelijks zien, nu in de woorden van Mozes. Hij herinnert Israël aan de wetgeving op de Sinaï en noemt de grote conflicten die tussen Israël en JHWH zullen ontstaan. 
23 Zorg ervoor dat jullie het verbond tussen Jнwн en jullie niet vergeten, 24 Want JHWH, jullie God, is een verterend vuur, een jaloerse God.

En dat wordt inderdaad tot ervaring, volgens vers 25-27 (samenvattend:)

Wanneer volgende generaties andere goden gaan vereren en JHWH jullie uit jullie land verdrijft...

Met daarna een nieuwe ervaring

29 ... en als jullie daar weer JHwH zoeken, zul je hem vinden, wanneer je zoekt met heel je hart ...

(31) 'want een barmhartig God is JHWH jouw God'.

Hij vergeet het verbond met jouw vaders niet.

Die rolverdeling is cruciaal: jullie kinderen gaan dit Sinaïverbond vergeten, maar JHWH is er de God niet naar om zijn eerdere verbond, dat met de vaders, te vergeten.

Maar ook de volgorde is cruciaal. Een 'verterend vuur' en daarna: een 'barmhartig God'. Dat zijn geen 'eigenschappen', dat is de volgorde van het leven. Zo is het gegaan (Deut. 30:6; Jer. 29:13), daarom is Israël er nog. Het is jammer dat de Heidelbergse Catechismus die bijbelse volgorde heeft omgedraaid: God is wel barmhartig, maar hij is ook rechtvaardig. ${ }^{5}$ Daar is de biografie verdwenen en hebben we het contextvrij over de mens in het algemeen in dispuut met God in het algemeen en over de lastige verhouding tussen diens 'eigenschappen', gemarkeerd met: maar ... Einde van alle verwondering.

Deze traditionele praktijk van contextvrij bijbellezen, binnen en buiten theologie en kerk, roept de vragen op die we meestal bespreken als 'hermeneutiek': hoe moet ik dit lezen? Dat is een verwarrende manier van doen, omdat we die vragen zelf hebben laten ontstaan door een a-historische en a-contextuele manier van lezen. Die suggereert dat vragen naar historische afstand of literaire achtergrond een interessante, maar theologisch geen fundamentele opdracht is, alleen voor de exegese en dat de echte vraag naar wat deze teksten nu voor de huidige lezer betekenen, een heel ander vak is: hermeneutiek of homiletiek.

Dat is een klassieke, maar fundamentele fout in de theologie. Om twee

5 Vraag 11. Is dan God ook niet barmhartig? Antwoord: God is wel barmhartig, maar Hij is ook rechtvaardig. 
redenen. De eerste reden is dat men zo het verschil tussen de productieprocessen van de bijbeltekst en de theologische uitleg van de voltooide tekst veel te groot maakt en daarmee de continuïteit van de leesgemeenschappen met hun ervaringen, hun schrijven, hun lezen en hun klagen of zingen, ongedaan maakt. De tweede reden is dat men zo ongemerkt de bijbeltekst als levensecht rollenspel inruilt voor een tekst met beweringen of 'een boodschap', waar ik vervolgens als lezer in mijn eigen 'context' wel of niet iets mee kan. Dat een actuele lezer zo gaat reageren is wel begrijpelijk, maar wat er zo uitdagend is aan de omgang van God en mensen in bijbelteksten, is dan allang verdwenen achter theologische tradities of achter urgente kwesties. Zo is het vooral de rol van Gods 'ik' die uit beeld verdwijnt: God is een derde persoon geworden, een boodschap. En daarmee worden de teksten waarin God zichzelf uitspreekt, vragen stelt, verwijten formuleert, zichzelf herneemt omdat hij toch verder wil met Israël, geneutraliseerd tot 'bron van Godskennis'. Materiaal waarmee mensen nu actueel over God proberen te spreken, in plaats van de erkenning dat het in de Bijbel andersom gaat.

Dat is het punt waar Arnold Huijgen gelijk heeft: bijbellezen is een ontmoeting, een activiteit op zichzelf, niet in dienst van enig ander belang. Tegelijkertijd moet wel een volgende vraag worden gesteld: hoe beslissend is mijn 'ik' in dit proces? Beslist de openheid van de lezer eigenlijk over de actualiteit van de bijbeltekst? Dat is niet wat Huijgen bedoelt, maar toch, moet je niet veel langer de geschiedenis van de gesprekken tussen God en Israël beluisteren?

\section{Bijbelwetenschap - Gods 'Ik' in tekst en geschiedenis}

De zorg van Arnold Huijgen deel ik: gaat het oude boek in kerk en theologie pas open als we een probleem hebben, of in een liturgisch ritueel volgens een leesrooster? Is ons Bijbellezen niet een geloofsactiviteit, met openheid voor ontmoeting? Dat roept wel een volgende vraag op: door welke teksten 'laat ik mijzelf lezen', zoals Huijgen dat formuleert, en besef ik wel dat ik niet de eerste ben en dat deze teksten een heel lange geschiedenis van lezen en schrijven hebben?

Stelling: 'Je laten lezen', is een houding die niet pas ingaat bij de actuele lezer. Bijbelonderzoek van de vele manuscripten en vertalingen laat zien dat die houding ook de motor is van het hele schrijf-, redactie- en overleveringsproces van de bijbelteksten.

De ontmoeting van God en mensen is iets anders dan het doen van mededelingen of het ontvangen van inzicht. Een bijbellezer gaat aan boord van een geschiedenis die allang gaande is. Het proces van tekstwording is een interactief gebeuren en toont reacties en emoties aan beide zijden. De tekst van 
Jeremia 2 laat daar iets van zien: bij sprekers en hoorders, bij schrijvers en lezers.

2. Ga en maak bekend aan Jeruzalem:

Als volgt heeft JHwH gesproken: Ik herinner mij de liefde van je jeugd, jouw liefde als bruid, hoe je mij volgde in de woestijn, in onbezaaid land. $[\ldots]$

11. Heeft een natie ooit goden ingeruild, terwijl die geen goden zijn? Maar mijn volk heeft zijn/mijn eer ingeruild voor wat geen hulp kan bieden.

De Jeremiatekst verwoordt Gods teleurstelling en zijn onbegrip ('heeft ooit...'). Tegelijkertijd laat de tekstoverlevering van vers 11 een aanpassing zien van 'Ik' = God naar een 'hij' = Israël. 'Mijn volk heeft mijn eer ingeruild' is veranderd in: 'mijn volk heeft zijn eer ingeruild.' De teleurstelling van God is een verwijt aan Israël geworden. Deze tekst vertelt zo tegelijkertijd iets over God en over de schrijvers. JHwH toont zijn verbijstering, de schrijvers lijken God te beschermen tegen al te menselijke trekken: kan dat, mensen die Gods eer inruilen? Jeremia 2:11 is een van de voorbeelden van de zogenaamde Tiqqune soferim, de verbeteringen door de schrijvers. ${ }^{6}$ Daar zijn er meer van, bijvoorbeeld in Zacharia 2:8 'mijn oogappel' of 'zijn oogappel'; Psalm 106: 19-21 'zijn eer' of 'hun eer'. Gods spreken en menselijke traditie blijken voortdurend met elkaar verstrengeld in de tekstoverleveringen. Is dat een probleem? Moeten we dat uitzuiveren? Nee, we moeten wel weten dat het zo gaat.

De interactie tussen menselijke geschiedenis en Gods spreken is in de Bijbel voortdurend aan de orde, met alle spanningen die dat oplevert. Voor bijbellezers is dat vaak ingewikkeld, maar het is wel levensechte biografie. Daarin vallen soms stevige woorden, zoals 'verwerpen', 'afwijzen'. In het boek Samuël $(I, 8)$ wordt verteld, dat het volk Israël dringend behoefte heeft aan een koning, 'iemand die onze oorlogen kan voeren.' Samuël is ertegen, maar tussen alle discussies door klinkt drie maal uit de mond van JHwH: 'Luister naar hun stem' (vs. 7, 9, 22). 'Ze hebben niet jou verworpen, maar mij: ik mag geen koning over hen zijn.' Onder de echo van deze woorden gaat de geschiedenis van God met Israël verder, met in de boeken Samuël en Koningen tot het einde de spanning: accepteert de koning de zeggenschap van de Tora (I Samuël 12, I Koningen 2:1-4), of niet? Gelovig en open bijbellezen kan deze spanningen niet uit de weg gaan. Ze horen bij wat Psalm 78 de 'verborgenhe-

6 P.H. Kelly, D.S. Mynatt, T.G. Crawford, The Massorah of Biblia Hebraica Stuttgartensia. Introduction and Annotated Glossary, Grand Rapids 1998, 191. 
den' noemt, die van ouders op kinderen moeten worden overgeleverd, opdat ze niet worden als hun ouders, vers 7 . Traditie en ervaringen zijn dé spanning van Psalm 78. Huijgen spreekt echter via dat opdat over Psalm 78 als een psalm over hoop: 7 'Dat is de bedoeling van de Schriften: Op God hopen - niet als bronnenboek voor historische kennis.' Maar die tegenstelling is niet fair. 'Je laten lezen', vereist wel dat je de hele psalm doorwerkt. Historische kennis van de tekst en de generaties laat zien dat de psalm niet over hoop gaat. Er ligt een harde vraag. Houdt de Tora het vol? Als die volgende generaties niet op God vertrouwen, wil God dan nog wel verder? Vers 59 geeft het antwoord: God, geschoffeerd, verwierp Israël. De psalm is geen les in zondebesef, dit is crisis: heeft God nog een optie, of houdt het met de verwerping op? Vers 65: God schrok wakker als een dronken strijder. Hij doet onverwacht iets heel aparts; hij kiest David als herder. God herneemt zich, en doet dat meer dan eens, zo vertelt Ezechiël 20.8

Als het bijbelonderzoek je zo bepaalt bij de geschiedenis van de rolverdeling tussen God en Israël, wat betekent dat voor gelovig bijbellezen en voor het vak hermeneutiek?

\section{Na de hermeneutiek: krijgt de ziel nu het laatste woord?}

In de loop van de geschiedenis ervaren gelovigen steeds weer de uitdaging om te reageren op de eigen cultuur. Wat betekent nu geloven in God? Hier gaan de wegen nadrukkelijk uiteen. Soms is hermeneutiek een helpdesk voor acute vragen rond Bijbel en moderne cultuur: het gegeven van verschillende vormen van seksualiteit, de verhouding van kerk en staat, geloof en wetenschap. Wat zegt de Bijbel over ...? Voor exegeten is hermeneutiek een vak waarin methodisch wordt nagedacht over tekstuitleg en methoden. Zoals Oeming ${ }^{9}$ het formuleert: Wann aber können wir sagen, daß wir die Bedeutung der Worte gefunden und einen biblischen Text richtig verstanden haben? Dat is dan wel hermeneutiek met de lezer in de eerste persoon 'wir' en God als derde persoon. Vragen naar de rolverdeling in de teksten en hun geschiedenis wordt vermeden. Daarom is het ook niet zo gek dat aan de liberale kant van het spectrum de hermeneutiek zo ongeveer het einde is van de hermeneutiek als

7 Huijgen, 57. Met een verwijzing naar Paulus, 58; beter zou zijn het citaat in Matth. 13:35 over de gelijkenissen als geheimen.

8 In dit verband is het boeiend om te lezen dat Arnold Huijgen afstand neemt van het accommodatie-denken bij Calvijn e.a. (76). Dat lijkt me terecht. Eep Talstra, De Éne God is de andere niet. Theologie en rolverdeling in Jeremia 5: 1-9. Rede, 7 oktober 2011, Amsterdam, 2011, 34vv.

9 Manfred Oeming, Biblische Hermeneutik. Eine Einführung, Darmstadt 2007-2, VII. 
vak. Want hoe aannemelijk zijn onze beweringen over God, juist als we die uit antieke Bijbelteksten extraheren? Volgt de klassieke hermeneutiek niet een fictie: zoeken naar een oorspronkelijke tekst en een eenduidige uitleg? ${ }^{10}$

Kerk en theologie lijken een beetje moe te worden van al die 'hermeneutieken'. Links en rechts, van liberaal christendom tot en met theologie van de spirituele beleving, begint men zich af te vragen of je met interpretatie van teksten en met hermeneutische technieken nog wel ergens komt. Er ontstaat een afwending van tekstinterpretatie naar beleving, liturgie. Of, van tekstinterpretatie naar religie en ervaring. Tot mijn verbazing komen ze allemaal uit bij 'de ziel'. In de woorden van Plaisier: interpretatie en hermeneutiek worden een anachronisme; het gaat nu om spiritualiteit en de ziel. ${ }^{11}$ Van liberale theologen kan de theologie 'voorbij de hermeneutiek' wel ophouden met tekstpuzzels, want zoals bij Augustinus is liefde de leidraad van onze Bijbeluitleg. ${ }^{12}$ Niet meer lezen als schriftgeleerde, maar wel open voor 'de ziel van de ander'. Arnold Huijgen noemt zijn boek 'een kleine hermeneutiek' (14) en begint ook al over de ziel als dé plek van contact tussen God en mens.

Theologen hebben een probleem met de Bijbel, dat is wel helder. Maar waarom eigenlijk? Omdat de historisch-analytische vraagstelling in het vak Bijbelwetenschappen te lang als tegenstander van het geloof is ervaren, waardoor het binnen kerk en theologie inhoudelijk niet mee kon of wilde doen. Anders kan ik het dedain waarmee van links tot rechts zo vaak over 'schriftgeleerden' wordt gesproken niet plaatsen. Zelfs Stefan Paas ${ }^{13}$ schrijft: 'Theologie is immers niet alleen te vinden in oude teksten, maar ook in levende mensen.' Ja, alleen is dat precies wat bijbelonderzoekers al zo lang laten zien: er is geen 'maar'; zo is dat altijd gegaan. Daarom is de Bijbel een biografie met alle soorten ervaringen, conflicten en dialogen die daarbij horen.

De moderne wending naar religie en ziel, of naar liturgie en ziel, egaliseert die biografie tot alleen ons spreken over God. De kritische hoofdrolspeler die geen expressie wil zijn van menselijke religie, vervluchtigt tot ons verlangen of ons zoeken. Maar wie de teksten leest, ziet God steeds weer in conflict met religie, ook, of juist binnen Israël. Bijvoorbeeld Numeri 6: 22-27 makt een

10 Rick Benjamins, 'Waar wij ons bevinden. Een lokalisatie op de theologisch landkaart', in: Rick Benjamins, e.a. (red.), Liberaal Christendom. Ervaren, doen, denken, Vught 2016, 12-41; 'voorbij de hermeneutiek', 29vv.

11 Arjan Plaisier, Zorg voor de ziel, Utrecht 2020.

12 Wouter Slob, 'De Bijbel als woord van God', 103-112, in: Rick Benjamins, e.a. (red.), Liberaal Christendom, 103-112; zie 110, 111.

13 Stefan Paas, Zoeken naar het Goede Leven. De toekomst van Theologie, Utrecht 2019, 34. 
opvallend onderscheid tussen de spelers in de tekst. Na de priesterzegen staat er: 'En zo moeten ze mijn naam op de Israëlieten vestigen, maar ikzelf zal hen zegenen.' 'Ikzelf', dat staat in duidelijk contrast met het antieke religieuze gebruik van de zegentekst als amulet, als zelfwerkzame woorden. ${ }^{14}$

Daarom: rationeel werken en historisch-kritische methoden horen in één domein samen met gelovig en ontvankelijk bijbellezen en met kritische gesprekken over godsdienst in onze cultuur. Je kunt dat allemaal 'hermeneutiek' blijven noemen. 'Bijbeluitleg in de publieke ruimte' lijkt me beter.

E. Talstra was buitengewoon hoogleraar 'Bijbel en alfa-informatica' en hoogleraar Oude Testament aan de VU tot zijn emeritaat in 2011.

14 Eep Talstra, Oude en Nieuwe lezers. Een inleiding in de Methoden van Uitleg van het Oude Testament (Ontwerpen 2), Kampen 2002, 44, 52, 77. 